\title{
Maternal mortality in tertiary care hospital: a 2-year review
}

\author{
Juhi Ankit Patel*, Kanaklata D. Nakum, Aditi Vithal, Mayank R. Lunagariya
}

Department of Obstetrics and Gynecology, Maharaja Krishnakumarsinhji University, Bhavnagar, Gujarat, India

Received: 28 October 2018

Accepted: 28 November 2018

\section{*Correspondence:}

Dr. Juhi Ankit Patel,

E-mail: pateljuhi1530@gmail.com

Copyright: (c) the author(s), publisher and licensee Medip Academy. This is an open-access article distributed under the terms of the Creative Commons Attribution Non-Commercial License, which permits unrestricted non-commercial use, distribution, and reproduction in any medium, provided the original work is properly cited.

\section{ABSTRACT}

Background: Epidemiological data pertaining to maternal mortality is valuable in each set up to design interventional programs to favourably reduce the ratio. This study was done to evaluate the maternal mortality rate in our hospital, to assess the epidemiological aspects and causes of maternal mortality, and to suggest recommendations for improvement.

Methods: This was a 2-year retrospective study. Epidemiological data was collected from the Last 2 years of Facility Based Maternal Death Review Form. Maternal mortality ratio, epidemiological factors and causes affecting maternal mortality were assessed.

Results: A total of 72 maternal deaths occurred. Most maternal deaths occurred in the age group of 20-24 years $(40.27 \%)$, multiparous women $(70.83 \%)$, women from rural areas $(65.27 \%)$, illiterate women, unbooked patients $(83.33 \%)$, and patients of low socioeconomic status. Direct causes accounted for $62.4 \%$ of maternal deaths where as $37.4 \%$ of maternal deaths were due to indirect causes.

Conclusions: There is a wide scope for improvement as a large proportion of the observed deaths could be preventable.

Keywords: Maternal mortality ratio, Maternal mortality, Prevention

\section{INTRODUCTION}

According to the World Health Organization (WHO), "A maternal death is defined as death of a woman while pregnant or within 42 days of termination of pregnancy, irrespective of the duration and site of pregnancy, from any cause related to or aggravated by pregnancy or its management" (ICD 10).

Almost half a million women die every year from complications during pregnancy and childbirth. About $99 \%$ of these women are from developing world with over $90 \%$ concentrated in Africa and Asia. The current maternal mortality ratio (MMR) in India has declined from 167 in 2011-2013 to 130 in 2014-2016 according to a special bulletin issued by Health Ministry of India. ${ }^{1}$ The tragedy is that these deaths are largely preventable. The progress in maternal health has been uneven, inequitable, and unsatisfactory. Nearly 45,000 mothers die due to causes related to childbirth every year that accounts for $17 \%$ of such deaths globally. United Nation (UN) report card on Millennium Development Goal 5 concluded that little progress had been made in sub-Saharan Africa where half of all maternal deaths take place. $^{2}$ The progress shown by the South Asian countries including India which accounts for $25 \%$ of all maternal deaths is also not impressive. ${ }^{3}$

Most of the evidence for maternal mortality is obtained through hospital data and maternal deaths are from rural areas. This study was done to assess maternal mortality in a tertiary care hospital situated where large numbers of patients are referred from rural parts of Bhavnagar.

This study was done to assess the local causes of maternal mortality and suggest remedial measures to 
reduce the same. The objective of the present study was to calculate the maternal mortality rate in our hospital, to assess the epidemiological aspects of maternal mortality, to assess the causes of maternal mortality, to suggest ways to reduce the MMR.

\section{METHODS}

The present hospital is an urban, tertiary care center; situated in the middle part of Bhavnagar. It gets a large number of referrals from maternity homes, Primary health centers from rural and urban area and also from Community Health Center. The present study was a retrospective study, conducted in the department of Obstetrics and Gynecology of this hospital.

Data regarding maternal mortality was collected from last 2 years of Facility Based Maternal Death Forms. The details of maternal deaths from January 2016 to December 2017 were collected and analyzed with respect to following epidemiological parameters:

- Locality wise distribution of maternal deaths.

- Gravidity wise distribution of maternal deaths.

- Maternal deaths according to antenatal care taken or not.

- Distribution of maternal deaths according to socioeconomic status.

- Causes of maternal deaths.

Descriptive data was tabulated as absolute figures and percentages. The details of number of live births from January 2016 to December 2017were collected from labor ward register. Maternal mortality rate for the study period was calculated by using the formula

- Total no. of maternal deaths/total no. of live births* 100000 .

\section{RESULTS}

During the study period, January 2016 to December 2017 , there were a total of live births and 72 maternal deaths.

The epidemiological characteristics of maternal deaths are shown in Table 1.

Table 1: Age group and maternal death.

\begin{tabular}{|lll|}
\hline Age (years) & No. & Percentage \\
\hline$<20$ & 01 & 1.38 \\
\hline $20-24$ & 29 & 40.27 \\
\hline $25-29$ & 20 & 27.77 \\
\hline $30-34$ & 10 & 13.88 \\
\hline $35-39$ & 08 & 11.11 \\
\hline$>40$ & 04 & 5.55 \\
\hline Total & 72 & 99.96 \\
\hline
\end{tabular}

Maximum maternal deaths $(40.27 \%)$ were reported in the age group of 20 to 24 years. Table 2 more deaths were reported in multiparous women $(70.83 \%)$ as compared to Primiparas.

Table 2: Relationship between mortality and gravida para status.

\begin{tabular}{|lll|}
\hline & Gravida & Para \\
\hline Primi & 23 & 21 \\
\hline Second & 15 & 17 \\
\hline Third & 22 & 23 \\
\hline Third & 12 & 11 \\
\hline
\end{tabular}

(29.17\%), Table 3 More maternal deaths were reported in women from rural areas $(65.27 \%)$ as compared to women from urban areas $(34.72 \%)$.

Table 3: \% of Death occurring in hospital by urban and rural sector.

\begin{tabular}{|lll|}
\hline Age & Urban & Rural \\
\hline$<20$ & 00 & 01 \\
\hline $20-24$ & 08 & 21 \\
\hline $25-29$ & 07 & 13 \\
\hline $30-34$ & 05 & 05 \\
\hline $35-39$ & 03 & 05 \\
\hline$>40$ & 02 & 02 \\
\hline Total & $25(34.72 \%)$ & $47(65.27 \%)$ \\
\hline
\end{tabular}

Table $4(56.94 \%)$ Of Death occurred in women not receiving ANC. Maximum maternal deaths were reported in unbooked patients $(83.33 \%)$ as compared to booked patients $(16.66 \%)$. Most maternal deaths were reported in women with low socioeconomic status (Table 5).

Table 4: Mortality among Patient with or without ANC.

\begin{tabular}{|lll|}
\hline ANC taken & No. of Patient & $\%$ of Patient \\
\hline Yes & 31 & 43.05 \\
\hline No & 41 & 56.94 \\
\hline
\end{tabular}

Table 5: Mortality related to booked or unbooked cases.

\begin{tabular}{|lll|}
\hline & No. & $\%$ \\
\hline Booked case & 13 & $16.66 \%$ \\
\hline Unbooked case & 59 & $83.33 \%$ \\
\hline
\end{tabular}

As shown in Table 6 In the study period, $62.4 \%$ of maternal deaths were due to direct causes.

The classical triad of haemorrhage (25\%), Eclampsia and Preeclampsia toxemia(20.8\%), and sepsis (16.6\%\%) was the major direct causes of maternal deaths, whereas only one maternal death $(1.3 \%)$ was due to ruptured ectopic pregnancy and indirectly 4 maternal death was due to 
Abortion related complications. Most of these deaths can be preventable by measures provided early interventions.

Table 6: Direct causes of maternal deaths.

\begin{tabular}{|lll|}
\hline Direct causes & No. & Percentage \\
\hline Hemorrhage & 18 & 25 \\
\hline Eclampsia/ PET & 15 & 20.8 \\
\hline Septicemia & 12 & 16.6 \\
\hline Rupture Uterus & 00 & 00 \\
\hline Total & 45 & 62.4 \\
\hline
\end{tabular}

As shown in Table 7 In the study period, $37.42 \%$ of maternal deaths were due to indirect causes. Anemia, jaundice, and heart disease accounted for $16.6 \%, 11.11 \%$, and $5.55 \%$ of maternal deaths respectively and miscellaneous cause like Burns, Poisoning accounted for $4.16 \%$ of maternal deaths. Anemia is measure indirect cause in developing countries which is preventable by early interventions.

Table 7: Indirect causes of maternal deaths.

\begin{tabular}{|lll|}
\hline Indirect causes & No. & Percentage \\
\hline Anemia & 12 & 16.6 \\
\hline Jaundice & 8 & 11.11 \\
\hline Heart Disease & 4 & 5.55 \\
\hline Miscellaneous & 3 & 4.16 \\
\hline Total & 27 & 37.42 \\
\hline
\end{tabular}

\section{DISCUSSION}

Maternal mortality is an index of reproductive health of the society. High incidence of maternal deaths reflects poor quality of maternal services, late referral and low socioeconomic status of the community. ${ }^{15}$ The current maternal mortality ratio (MMR) in India is $130 / 100,000$ live births. 1 Various studies done in India in the last 15 years have shown wide variation in MMR ranging from $47 / 100000$ to $625 / 100000$ births. $^{4-9}$ Madhu Jain has reported a very high MMR of $2270 / 100000 .^{5}$ This study has comparatively high MMR, which could be due to the fact, that our hospital is a tertiary care hospital and receives a lot of complicated referrals from rural areas of Bhavnagar and also from Patients coming at a very late stage.

In present study, $50 \%$ of maternal deaths were in the age group of 20 to 29 years, as highest numbers of births are reported in this age group. Similarly, $70.83 \%$ of maternal deaths were reported in multiparous patients. More maternal deaths were reported in women from rural areas $(65.27 \%)$, unbooked patients $(83.33 \%)$, illiterate women and women belonging to low socioeconomic status. All our findings were similar to studies by Jain, Jadhav, Pal, Onakewhor..$^{5-8}$ In present study, $62.4 \%$ of maternal deaths were due to direct causes. Hemorrhage (25\%), Eclampsia $(20.8 \%)$, and sepsis $(16.6 \%)$ were the major direct causes of maternal deaths. Our findings were consistent with studies by Jain, Jadhav, Pal, Onakewhor. ${ }^{5-8}$ Even today large number of maternal deaths is due to the classical triad of hemorrhage, sepsis, and eclampsia. ${ }^{10}$ All these are preventable causes of maternal mortality provided the treatment is instituted in time. Unfortunately, in many cases, patients were referred very late, in critical condition, unaccompanied by health care worker. ${ }^{14}$ Many patients had to travel a distance of 70 to 80 kilometers in a private vehicle to reach our tertiary center. Most of these deaths are preventable if patients are given appropriate treatment at periphery and timely referred to higher centers. ${ }^{13}$ Training of medical officers and staff nurses working in rural areas by programs like basic emergency obstetrics care (BEMOC) and skilled attendant at birth $(\mathrm{SAB})$ training gives a ray of hope of reducing maternal mortality. Indirect causes accounted for $27.5 \%$ of maternal deaths in present study. Anemia, jaundice, and heart disease were responsible for $10 \%$, $9.16 \%$, and $3.33 \%$ of maternal deaths, respectively. ${ }^{12}$ These findings were consistent with studies by Jain, Jadhav, Pal, Onakewhor. ${ }^{5-8}$

Maternal deaths can be prevented by improving the health care facilities in rural areas by ensuring round the clock availability of certain basic drugs like injection Oxytocin and magnesium sulfate, tablet misoprostol as most maternal deaths in rural areas are still due to eclampsia and postpartum hemorrhage. Early detection of high-risk pregnancies and referring them to a tertiary center at the earliest can reduce the complications of high-risk pregnancies.

National Rural Health Mission (NRHM) can play a major role in reducing maternal mortality by advocating institutional deliveries and timely referral of high-risk cases. Although we have not actually evaluated the impact of aforementioned educational programs on maternal mortality, it would be interesting to direct future studies in this regard.

\section{CONCLUSION}

Even today most maternal deaths are seen in patients from rural areas, unbooked, illiterate patients and patients from low socioeconomic status. Hemorrhage, Eclampsia and sepsis are the major causes of maternal deaths. Improvement in primary health care in rural areas and proper implementation of NRHM programs, early referral and up gradation of hospitals in rural areas can definitely bring down the number of maternal deaths.

Funding: No funding sources

Conflict of interest: None declared

Ethical approval: The study was approved by the Institutional Ethics Committee

\section{REFERENCES}

1. Special Bulletin on Maternal Mortality in India 2018, Sample registration system, Office of Registrar General, India; 2018. 
2. Ronsmans C, Graham WJ, Lancet Maternal Survival Series steering group. Maternal mortality: who, when, where, and why. The lancet. 2006;368(9542):1189-200.

3. The Millennium Development Goals Report 2009.New York: United Nations; 2009.

4. Puri A, Yadav I, Jain N. Maternal mortality in an urban Tertiary care hospital of north India. J Obstet Gynaecol India 2011;61(3):280.

5. Jain M, Maharahaje S. Maternal mortality: A retrospective analysis of ten years in a tertiary hospital. Indian J Prev Soc Med. 2003;34(3-4):10311.

6. Jadhav AJ, Rote PG. Maternal mortality-changing trends. J Obstet Gynaecol India. 2007;57(5):398-400.

7. Pal A, Ray P, Hazra S, Mondal TK. Review of changing trends in maternal mortality in a rural medical college in west Bengal. J Obstet Gynecol India. 2005;55:521 4.

8. Onakewhor JU, Gharoro EP. Changing trends in maternal mortality in a developing country. Niger $\mathrm{J}$ Clin Pract. 2008;11(2):111-20.

9. Shah RJ, Ali I, Banday A, Fazili A, Khan I. Analysis of maternal mortality in a small teaching hospital attached to tertiary care hospital. Indian J Community Med 2008;33(4):260 2.
10. Roberts JM., Pearson G., Cutler J., Lindheimer M. Summary of the NHLBI working group on research on hypertension during pregnancy. Hypertension 2003;41(2):437-45.

11. Kalur JS., Martin JN. Jr., Kirchner KA., Morrison JC. Postpartum pre-eclamsia-induced shock and death: A report of three cases. Am J Obstet Gynecol 1991;165(5):1362-8.

12. Venkatraman V., Levi J., Nanavati MS., Purandare CB., Daftary SN. Heart disease in pregnancy. J Obstet Gynecol India 1986; 36: 973-7.

13. Yadav S, Bachani D, Yadav BS, Nagar S. An analysis of risk factors determinantal on outcome of pregnancy. J Obstet Gynecol India 1986;36:296-9.

14. Reeta Bhuyan, Gitanjali Deka, Maternal deaths in a tertiary health care centre of Assam - a one year report. New Ind J OBGYN. 2016; 2(2):1104

15. Atrash HK., Alexander S., Berg CJ. Maternal mortality in developed countries: not just a concern of the past. Obstet Gynecol. 1995;86(4):700-5.

Cite this article as: Patel JA, Nakum KD, Vithal A, Lunagariya MR. Maternal mortality in tertiary care hospital: a 2-year review. Int J Reprod Contracept Obstet Gynecol 2019;8:184-7. 